PF 2019 (LXXIII): 91-98

\author{
PAULINA GROBELNA-MAZUREK \\ Instytut Historii \\ Uniwersytet im. Adama Mickiewicza w Poznaniu \\ Polska Akademia Nauk - Biblioteka Kórnicka \\ w Kórniku \\ tel. (+48) 6182914 93, (+48) 61531971492 \\ e-mail:pgmazurek@gmail.com
}

\title{
SEOWARZ Z 1532 ROKU \\ ZE ZBIORÓW BIBLIOTEKI NAUKOWEJ \\ W OŁOMUŃCU
}

SŁOWA KLUCZOWE: Słowarz, Florian Ungler, XVI-wieczna leksykografia, słowniki, Ultissimus vocabularius

KEYWORDS: Stowarz, Florian Ungler, the $16^{\text {th }}$ century lexicography, dictionaries, Ultissimus vocabularius

\section{2'S SŁOWARZ FROM RESEARCH LIBRARY IN OLOMOUC} ABSTRACT: The aim of this article is to explore the first edition copy of Latin-Italian-
Polish-German dictionary from 1532, recently discovered in Vědecká knihovna
v Olomouci (Research Library in Olomouc). The unique known copy of this print,
stored in Seminary's Library in Włocławek, disappeared after the Second World War.
A few last cards of another copy were found by Marcin Jakubczyk in 2014 in Budapest.
The defected Olomoucian print is the third independent copy of Dictionarius.
Together with Budapestian fragment it gives opportunity for the research on the one
of the first lexicographic monuments of Polish language which has not been examined
yet. 
Wytłoczone w 1532 roku w krakowskiej oficynie Floriana Unglera ${ }^{1}$ pierwsze wydanie anonimowego ${ }^{2}$ łacińsko-włosko-polsko-niemieckiego Słowarza uchodziło aż do dnia dzisiejszego za zaginione. Jako jedyny omówił je w 1899 roku na łamach „Prac Filologicznych” Hieronim Łopaciński (Łopaciński 1899, s. 399-404). Egzemplarz zdefektowany, znajdujący się w wówczas w Bibliotece Seminarium we Włocławku, zaginął w czasie wojny. Jego brakująca część, jak sygnalizował za Estreicherem (ESTREICHER XV, s. 202) Łopaciński, miała znajdować się wówczas „W bibliotece Akademji Umiejętności w Peszcie” (Łopaciński 1899, s. 400). Informację tę skorygował Estreicher tuż przed wojną w następujący sposób: „Cztery kartki (ark. L) z tego dziełka miał niegdyś Franc[iszek] Flor[ian] Romer $^{3}$ zamieszkały na Węgrzech, jak doniósł memu ojcu. Co się z nimi stało, nie wiadomo (w Bibl. Muz. Peszt. ani w Akad. peszt. ich nie ma, jak mnie poinformował w r. 1910 bibliotekarz Jan Melich)"4 (ESTREICHER XXXIII, s. 238).

Stulecie później odnalazł je tam jednak (ściślej zaś w dzisiejszej Węgierskiej Bibliotece Narodowej Ferenca Széchényiego) Marcin Jakubczyk (pod sygn. Ant. 6329). Było to „10 stron (wraz z kartą z kolofonem (...). Strony te trafiwszy do Budapesztu prawdopodobnie jako niepołączone ze sobą (tzn. w formie luźnych kartek), zostały (...) niewłaściwie ze sobą scalone, a następnie ponumerowane (ołówkiem) przez pracowników Biblioteki (nie wiadomo, w jakim okresie)" (Jakubczyk 2012, s. 164). Ustalenie ich właściwej kolejności możliwe było dzięki zestawieniu zaginionego fragmentu z drugim wydaniem Słowarza (SŁOWARZ (II)) oraz jego pierwowzorem: rzymskim Vochabuolista z 1510 roku $^{5}$ i dwoma późniejszymi wydaniami tegoż z 1516 i 1518 roku$^{6}$. Na jej podstawie M. Jakubczykowi udało się: 1) potwierdzić genetyczną zależność unglerowskiego wokabularza od wspomnianego wyżej słownika Mazochiusa (1510), a także jego drugiego wydania (SŁOWARZ (II)) od późniejszych wznowień Vochaboulisty (1516,

1 Florian Ungler (?-1536) - drukarz krakowski pochodzący z Bawarii, żonaty najpierw z Magdaleną Wąsówną (zm. 1522 r.), później z Heleną, która po jego śmierci w 1536 roku przejęła drukarnię. Zob. DDP, s. 313; Piekarski 1926; EWOK, s. 2406-2407; SPKP, s. 926-927.

2 Autorstwo słownika pozostaje w dalszym ciągu sprawą otwartą. M. Plezia (1959, s. XII) przypisał go za Estreicherem (ESTREICHER XXXIII, s. 238) Janowi Cervusowi (?-1557). Por. E. Kędelska (1986, s. 81), która była skłonna odrzucić tę hipotezę.

3 Flóris Ferenc Romer (1815-1889) - ur. w Bratysławie, ksiądz, węgierski historyk sztuki i archeolog. János Melich (1872-1963) - ur. w Szarvas, językoznawca, w latach 1919-1922 pełnił funkcję dyrektora Węgierskiej Biblioteki Narodowej Ferenca Széchényiego.

5 UV (I). Egzemplarz przechowywany w Cambridge University Library pod sygn.: F151 d 21. Na zależność między tymi dwoma słownikami wskazały: A. Rossebastiano-Bart oraz E. Kędelska (Jakubczyk 2014, s. 162; E. Kędelska 1986, s. 81-87). Adaptację obcego wokabularza widział w Słowarzu M. Plezia (1959, s. XII). E. Kędelskiej zawdzięczamy jego gruntowną analizę, opartą na wydaniu Scharffenberg wydaniu z 1566 roku (Kędelska 1986, s. 77-87; Jakubczyk 2014, s. 162).

6 UV (II), UV (III). Oba egzemplarze dostępne online za pośrednictwem Münchener Digitalisierungs Zentrum Digitale Bibliothek (Jakubczyk 2014, s. 165, przypis 24 i 25). 
1518) oraz 2) wykluczyć możliwość, jakoby fragment budapesztański był tym, którego brakowało Łopacińskiemu w egzemplarzu włocławskim.

Ustalenia tego badacza okazują się tym cenniejsze, że uzmysłowiły nam istnienie dwóch, a nie - jak dotąd sądziliśmy - jednego egzemplarza słownika Unglera z 1532 roku. Faksymile budapeszteńskich kart, opublikowane w aneksie do jego artykułu, wydatnie przyczyniły się do zbadania innej, obszerniejszej części wokabularza, przechowywanej w Bibliotece Naukowej w Ołomuńcu (Vědecká knihovna v Olomouci) pod sygnaturą: 601.469/přívazek 3.

Druk, w oprawie z brązowej skóry (16 w.), liczy [49] k., w formacie $8^{\circ}$. Na karcie tytułowej (k. [1]a) znajduje się tytuł, zapisany w języku polskim i łacińskim: „Dictionarius seu $\mid$ nomenclatura quatuor lingua | rum. Latine, Italice, Polonice, [et] Theu | tonice, aprime cuiuis utilissimus, eū | peregrinantibus, tum domi re | sidentibus, Adiecto vocałbulo indice. | Wokabularz nowy czterzech | ięzikow: Laczinskiego: Włoskiego: Polskiego: | Niemieczkiego, wszem w tey slawney koronie | y innym narodom barzo użytecžny.”. Po nim następuje 10-wersowy zwrot do czytelnika w języku łacińskim (Ad lectorem). Na dole strony: „Venūdat a Floriano Unglerio Calogra" (zob. także Łopaciński 1899, s. 399).

Na odwrocie karty tytułowej (k. [1]b) widnieją tytuły alternatywne (w języku polskim, łacińskim i niemieckim), w tym rozpowszechniony w literaturze właśnie dzięki Łopacińskiemu Słowarz: „Wielmi pozyteczny slowarz | tym ktorzi ządaią wyrozumieć, y naucžyć się | czczić procž chodzenia do szkoły, iako są prosczi | laici, y niewiasty. Też każdy łaczinnik može się naucżyć, Włoskiego, Polskiego, y Niemiecć | kiego, a zasię koždy snich łaczinskiego: naucżyć Bocziē | w tych kxiegach zawierają sie wszytki imiona | przezwiska y slowa: które mogą być wymowio | ne rozmaitym obycz̈aiem" (zob. także Łopaciński 1899, s. 399-400).

$\mathrm{Na}$ k. [2]a-b odnajdujemy objaśnienie niektórych znaków, które posłużyły drukarzowi do oddania specyfiki poszczególnych języków, po nim (k. [3]a-[8]b) spis rozdziałów, odpowiednio w języku: po łacinie (k. [3]a-[4]a), po włosku (k. [4] b-[5]b), po polsku (k. [6]a-7[a]) i po niemiecku (k. [7]b-[8]b).

Wokabularz ma charakter tematyczny i składa się z dwóch części. Pierwszą, opisaną przez Łopacińskiego (Łopaciński 1899, s. 400), tworzy 57 rozdziałów (k. $\left.\mathrm{A}_{1} \mathrm{a}-\mathrm{H}_{4} \mathrm{~b}\right)$, zawierających hasła dotyczące sfery religijnej i duchowej (rozdz. od 1-10) $)^{7}$ oraz związane z codziennym życiem człowieka (rozdz. 11-57) ${ }^{8}$.

\footnotetext{
7 "Capitulū 1. O bodze, o s. troyci, o moci y o bogacztwhwie.|Cap. 2. o swiętych y o imionach niewiast. | ca. 3. o dziewiczthwie y o imionach niewiast. | ca. 4. o paczierzu y o zdrowey Mariey. | ca 5. o siedmi śmiertelnych grzechach. | ca. 6. o piączi smyslach. | ca 7. o uczynkach miłosiernych. | ca. 8. o dziesięcziorgu przykazaniu božym. | ca. 9. o urzędzie kosczielnym. | ca. 10. o diable y o piekle y o cżysczu".

8 Ca. 11. o czasie: o roku, kxiężycu, y o dniu | ca. 12. o cžłowiecže y iego cžescziach wnętrz | nich y zewnętrznych | ca 13. o Cesarstwie, y i iego moci. (nych. | ca. 14. o cesarzewey, y o niewiescziech
} 
Część druga - znacznie krótsza - złożona jest z 8 rozdziałów (od k. I a do końca): „1. o slowiech, y o ich wažnosczi. | ca. 2. o poslech. | ca. 3. o weselu y o poczieszeniu. | ca. 4. o ymionach y o przezwiskach. | ca. 5. o nadziei. | ca. 6. o kucharzu y o iego nacžyniu. | ca. 7. o spaniu y o snie. | ca. 8. o rozmaytich imionach.”"

Zgodnie $\mathrm{z}$ opisem katalogowym w omawianych egzemplarzu Słowarza brakuje kilku końcowych kart, w tym karty $\mathrm{z}$ kolofonem ${ }^{10}$. Ostatnim rozdziałem jest rozdz. piąty - „O nadziei” $\left(\mathrm{k} . \mathrm{L}_{2}\right)$ - po którym następuje $1 \mathrm{k}$. nsygn. Odnotujmy również defekt w składce „C” (brak 2 k.), niewspomniany w katalogu.

W celu dokładnego określenia kolejności poszczególnych kart, jak również ustalenia braków, posłużyłam się metodą komparatystyczną, zestawiając omawiany egzemplarz ze wspomnianym już drugim wydaniem Słowarza z 1566 roku (SŁOWARZ (II)), budapeszteńskim fragmentem pierwszego wydania, opublikowanym przez M. Jakubczyka (Jakubczyk 2014, s. 170-172; dalej jako: Aneks) oraz informacjami, które zawarł w swoim artykule H. Łopaciński (Łopaciński: 1899, s. 399-404).

Na tej podstawie zarejestrowałam - w odniesieniu do ubytków w składce „C” - brak k. sygn. $\left[\mathbf{C}_{2}\right]$ i $\left[\mathbf{C}_{3}\right]$, uznając następującą po k. $C_{1}$ kartę, zawierającą hasła należące do rozdz. 17. („o miesczie, sędzach, y o sprawach”) za k. [ $\left.\mathbf{C}_{4}\right]$. W omawianym egzemplarzu brakuje zatem rozdz. 14-16 oraz początku rozdz. $17^{11}$.

slachet- | ca. 15. o przirodzonych, y o wszytkim rodzaju | ca. 16. o godziech, y o ich stadle. | ca. 17. o miesczie, sędzach, y o sprawach. | ca. 18. o liczbie składaney, y o pięniadzach, | ca. 19. o złoczie i o srebrze, y o wszystkich rzeczach które mogą bycz rospuszcžone . | ca. 20. o ziołach y o wszystkiey kupi. | ca. 21. o suknie, płotnie, y o innych rzeczach | im podobnych. | ca. 22. o kupczach, rzemieslnikach, y naukach. | ca. 23. o farbach. | ca. 24. o naczyniu y o szacziech domu. | ca. 25. o domiech. | ca. 26. o chlebie winie, y rzeczach iedzącich. | ca. 27. o organiech, y inszym naczyniu gędźby. | ca. 28. o kamieniach drogich, y innych rzeczach. | ca. 29. o zbroiach. | ca. 30. o rzeczach wielkich. | ca. 31. o ogrodzie, o drzewie, y o owoczach. | ca. 32. o vinniczach. | ca. 33. o liesie, y o iego rzeczach. | ca. 34. o zwierzętach. | ca. 35. o mrowkach y o innych robakach $\mid$ ca. 36. o ptacech y o iego rodzaju. | ca. 37. o rybach / y o ich rodzaiu. | ca. 38. o łodziach, y o małych łodkach. | ca. 39. o powietrzu y o wietrzech. | ca. 40. o gorach, y o walech. | ca. 41. o własności ziem. | ca. 42. o mieszcziech y o zamkach. | ca. 43. o krzesczianstwie y o wiernych. | ca. 44. o swadach o walkach y o kuglarzoch. | ca. 45. o gędzczach y o piscžkach. | ca. 46. o niemoczach y o chorobach. | ca. 47. o koscziele, y rzecžach czok niemu słužą. | ca. 48. o nauce i stole. | ca. 49. o wodzie y o wilkoci. | ca. 50. o ogniu i czieple. | ca. 51. o posluszeństwie. | ca. 52. o nierozumnych. | ca. o pałaczach. | ca. 53. o piwnici y o rzecžach które wniey są. | ca. 55. o izbie y kuchni, y o ich przisluszeństwie | ca. 56. o komorze, y iey rzeczach przisluszaiącz $\mid$ ca. 57. o nasieniu i ziarnie".

9 Nie do końca rację ma M. Plezia, który dzieli słownik na część rzeczową oraz tę zawierającą czasowniki i rozmówki (Plezia 1959, s. XI-XII).

10 „Chybí listy, 3 poslední kapitoly 2. knihy. Neúplné. Čísl. vrstvami”. Zob. internetowy katalog zbiorów Biblioteki Naukowej w Ołomuńcu (https://aleph.vkol.cz/F/1X9N73FHV5P2B3YX9QIILIFLTHIP185I6UM71UYEIS3KJ

L213-92898?func=scan-list, dostęp 21.02.2019).

11 O braku k. następującej po k. $\mathrm{C}_{1}$ informuje nas niepełny tytuł rozdziału czternastego: „Cl. 14. ca. e della Imperatrice: e donne ma-”, po którym winno następować „gnifiche e li servitori” (zob. k. [4]b). 
Co się tyczy wspomnianego już defektu kart końcowych, stwierdzić należy brak k. $\mathbf{L}_{\mathbf{3}} \mathbf{i ~ L}_{\mathbf{4}}$ (Aneks, facs. 3-6), po których następuje karta nsygn. [ $\left.\mathbf{L}_{5}\right]$ (Aneks, facs. 7) ${ }^{12}$. Za nimi powinna znajdować się druga karta nsygn. [ $\mathbf{L}_{6}$ ], zawierająca ostatni fragment rozdz. 8 oraz - na odwrocie - kolofon (Aneks, facs. 9, kolofon).

Na podstawie powyższego byłam w stanie ustalić ogólną liczbę kart pierwszego wydania Słowarza na 54 k. (sygn.: [1-8] k. nsygn., A-K ${ }^{1-4}, \mathrm{~L}^{1-6}$ ) oraz wykazać, że jego wersja ołomuniecka ani nie stanowi zaginionego po wojnie egzemplarza włocławskiego, ani brakującej części fragmentu budapeszteńskiego (zob. tab. 1). Mamy więc do czynienia z trzecim, zarejestrowanym egzemplarzem unglerowskiego druku z 1532 roku.

Tabela 1. Zestawienie egzemplarzy Słowarza $\left(\mathrm{k} . \mathrm{L}_{1}-\mathrm{L}_{-6}\right)$

\begin{tabular}{|l|l|l|}
\hline Egzemplarz: & Posiada: & Braki: \\
\hline włocławski & k. L4 & k. L1-L3, L5-L6 \\
\hline budapeszteński & k. L1-6 & - \\
\hline ołomuniecki & k. L1-2, L5 & k. L3-4, L6 \\
\hline
\end{tabular}

Pomimo iż w dalszym ciągu nie dysponujemy pełnym wydaniem Słowarza, to jednak po zestawieniu zdefektowanego druku ołomunieckiego z kartami przechowywanymi w Węgierskiej Bibliotece Narodowej Ferenca Széchényiego, a opublikowanymi przez M. Jakubczyka, uzyskujemy w miarę kompletny jego obraz (z wyjątkiem k. $\left[\mathrm{C}_{2}\right]$ i k. $\left[\mathrm{C}_{3}\right]$ ).

Dictionarius odznacza się charakterystycznym dla krakowskiej oficyny Unglera zasobem typograficznym, reprezentującym drugi okres jej działalności (1521-1536) ${ }^{13}$, ściślej zaś lata po 1531 roku, w którym uległ on niemal całkowitej wymianie (PT, s. 11). Wykorzystano w nim dwa zestawy czcionek: pismo 18 - nagłówkowe (PT, tab. 360) oraz tekstowe pismo 19 (PT, tab. 360) ${ }^{14}$. Odnotujmy jedynie nieco inną, dotąd nierejestrowaną formę majuskuły „D”. Na karcie [4]r. i k. [7]r. odbito plecionkę kaligraficzną (PT, tab. 313, drzew. 886). Na ostatniej zaś (z kolofonem), oprócz adresu wydawniczego, („Excussum Cracovie per | Florianūm Ungleriū: An- | no domini: 1532”), wpisanego w ozdobną drzeworytową ramkę, wytłoczono sygnet drukarski o wym. 81x80 mm (PT, tab. 311;

12 Oznaczone przez węgierskich błędnie jako $M_{1}$ i M.

13 Pierwszy okres drukarskiej działalności Floriana Unglera (także pod kątem typograficznym) omówił Piekarski (1926). Kłopoty finansowe Unglera zmusiły go do zamknięcia warsztatu. Między 1516 a 1521 rokiem pracował w oficynie Jana Hallera (ca 1467-1525). Po wygaśnięciu kontraktu (16.07.1520 r.) wznowił działalność własnej drukarni (PT, s. 11). Warto nadmienić, że w latach 1513-1516 Ungler współpracował również z Wolfgangiem Lernem (?- ante 1543).

14 Ewolucję i zastosowanie tej czcionki omówił w swoim artykule K Piekarski (1930, s. 420-424). 
Krzak-Weiss 2006, tab. V, syg. 4; Kiliańczyk-Zięba 2015, il. 8 i 28). Jest to jeden z siedmiu unglerowskich sygnetów używany w dziejach jego warsztatu poligraficznego ${ }^{15}$. Odnajdujemy go w drukach $\mathrm{z}$ lat 1531-1536. Na ozdobnym kartuszu przedstawiono inicjały autora („FV”), a całość otacza wieniec laurowy (Zob. także Krzak-Weiss 2006, s. 113; Kiliańczyk-Zięba 2015, s. 78-80).

Nie do końca ustalona pozostaje kwestia proweniencji ołomunieckiego egzemplarza. Na karcie poprzedzającej tytułową obok dawnych sygnatur („9.29. in VIII” oraz „Sc 14.133”), zapisano ołówkiem, nowożytnym krojem pisma: „Gregorius de Schamotuli”. Adnotacja ta odnosi się najprawdopodobniej do rektora Akademii Krakowskiej i późniejszego kanonika poznańskiego Grzegorza z Szamotuł (1485-1541), jednakże brak innych znaków proweniencyjnych oraz informacji ze strony biblioteki uniemożliwia jej weryfikację ${ }^{16}$. Na koniec odnotujmy również zamieszczoną na k. $\left[\mathrm{L}_{5}\right] \mathrm{v}$. szesnastowieczną glossę.

Słowarz z 1532 roku ma wartość unikatową dla historii języka polskiego i badań językoznawczych. Znany wyłącznie Łopacińskiemu, przez długi czas pozostawał na marginesie naukowych dociekań ${ }^{17}$. Na jego poszukiwania poświęciła wiele lat swojej kariery naukowej, zmarła w 2014 roku Elżbieta Kędelska, wybitna badaczka języka polskiego, związana z Instytutem Slawistyki PAN. W jednym ze swoim artykułów napisała:

Miłośnicy dawnej leksykografii trafią może kiedyś także na ślad tzw. „Słowarza”, druku Unglera z 1532 r., którego unikat zaginął po wojnie i (...) dotąd się nie odnalazł (Kędelska 2001, s. 79).

Fakt, iż w roku, w którym Pani Profesor obchodziłaby swoje 70. urodziny, ujrzał on w końcu światło dzienne, zdaje się mieć znaczenie symboliczne, otwierając jej naukowym spadkobiercom drogę do dalszych badań.

\section{Wykaz skrótów:}

DDP = Kawecka-Gryczowa, A. (red.). (1983). Drukarze dawnej Polski od XV do XVIII wieku: praca zbiorowa, t. 1, Małopolska, cz. 1, wiek XV-XVI. Wrocław: Zakład Narodowy im. Ossolińskich - Wydawnictwo PAN.

15 Krzak-Weiss 2004, s. 109-114 odnotowała i opisała pięć sygnetów drukarskich Unglera. Jej ustalenia zweryfikowała K. Kiliańczyk-Zięba (2015, s. 13, 36, 79-80 oraz 142-145), dodając do nich kolejne dwa (il. 11 oraz 56). Zob. także PT, tab. 338, drzew. 971.

${ }_{16} \mathrm{~W}$ tym miejscu pragnę podziękować Lukášowi Slámie z Univerzita J.E. Purkyně w Ústí nad Labem za pomoc w dotarciu do odnalezionego egzemplarza.

17 Wyjąwszy ustalenia wspomnianych już A. Rossebastiano-Bart i E. Kędelskiej, krótko scharakteryzował go M. Plezia (1959, s. XI-XVII). 
ESTREICHER XV = Estreicher, K. (1897). Bibliografia polska, t. XV. Kraków: Akademia Umiejętności.

ESTREICHER XXXIII = Estreicher, K. (1939). Bibliografia polska, t. XXXIII. Kraków: Akademia Umiejętności.

EWOK = Kawecka-Gryczowa, A., Więckowska, H., Pazyra, S. (red.). (1971). Encyklopedia wiedzy o książce. Wocław [i in.]: Zakład Narodowy im. Ossolińskich.

PT = Kawecka-Gryczowa, A. (red.), Bułhak, H. (oprac.). (1964). Polonia typographica saeculi sedecimi. Druga drukarnia Floriana Unglera 1521-1536, z. 7, Wrocław: Zakład Narodowy im. Ossolińskich.

SŁOWARZ (I) = Anonim. (1532). Dictionarius seu nomenclatura quatuor linguarum. Latine, Italice, Polonice, [et] Theutonice, aprime cuiuis utilissimus, eū|peregrinantibus, tum domi residentibus, Adiecto vocabulo [rum] indice. Wokabularz nowy czterzech ięzikow: Laczinskiego: Włoskiego: Polskiego, Niemieczkiego, wszem w tey slawney koronie y innym narodom barzo użytecžny. Kraków: Drukarnia Floriana Unglera.

SŁOWARZ (II) = Anonim. (1566). Dictionarius, seu nomenclatura quatuor linguarum Latine, Italice, Polonice, et Theutonice: Apprimè cuiuis uitilissimus, cum peregrinantibus, tum domi residentibus. Adiecto Vocabulorum Indice. Wokabularz Nowy cżtérzech ięzyków, Łácińskiégo, Włoskiégo, Polskiégo, Niemieckiégo, wszem w téy Sławney Koronie, y inszym Narodōm bårzo pożyteczny. Kraków: Drukarnia Stanisława Scharffenberga.

SPKP = Triechel, I. (1972). Słownik pracowników ksiażki polskiej. Warszawa-Łódź: PWN.

UV (I) = Anonim. (1510). Utilissimus vocabularius. Rzym : Jacobus Mazochius.

UV (II) = Anonim. (1516). Introductio quaedam utilissima sive vocabularius quattuor linguarum Latinae, Italicae, Gallicae et Alamanicae. Augsburg: Erhart Öglin.

UV (III) = Anonim. (1518). Introductio quaedam utilissima sive vocabularius quattuor linguarum Latinae, Italicae, Gallicae et Alamanicae. Augsburg: Erhart Öglin.

\section{Bibliografia}

Jakubczyk, M. (2014). O odnalezionym budapeszteńskim fragmencie Słowarza z 1532 roku, Prace Filologiczne 65, 161-172.

Kedelska, E. (2001). Nieznane edycje słowników: Mymera z 1530 r. i Murmeliusza z 1526 r., Studia z Filologii Polskiej i Słowiańskiej, 37, s. 61-79.

Kędelska, E. (1986). Łacińsko-polskie słowniki drukowane pierwszej połowy XVI wieku i ich stosunek do źródeł czeskich. Wrocław: Zakład Narodowy im. Ossolińskich.

Kiliańczyk-Zięba, J. (2015). Sygnety drukarskie w Rzeczypospolitej XVI wieku: źródła ikonograficzne i treści ideowe. Kraków: Societas Vistulana.

Krzak-Weiss, K. (2006). Polskie sygnety drukarskie od XV do połowy XVII wieku, Poznań: Wydawnictwo „Poznańskie Studia Polonistyczne”. 
Łopaciński, H. (1899). Najdawniejsze słowniki polskie drukowane, Prace Filologiczne, 5, 1899, 393-454 oraz 586-605 (Uzupełnienie).

Piekarski, K. (1930). Miscellanea bibliograficzne. V. Powieść rzeczy istej o założeniu klasztora na Łysej Górze, Przegląd Biblioteczny, 4, 1930, 420-437.

Piekarski, K. (1926). Pierwsza drukarnia Florjana Unglera 1510-1516. Chronologia druków i zasobu typograficznego. Kraków: Drukarnia W.L. Anczyca i Spółki.

Plezia, M. (1959). Dzieje leksykografii łacińskiej w Polsce. W: M. Plezia (red.). Słownik tacińsko polski (V-XXXIX), t. 1. Warszawa: PWN.

\section{Streszczenie}

Przedmiotem niniejszego artykułu jest pierwsze wydanie łacińsko-włosko-polsko-niemieckiego słownika z 1532 roku, odkryty niedawno w Bibliotece Naukowej w Ołomuńcu. Jedyny, znany dotąd egzemplarz tego druku, przechowywany w Bibliotece Wyższego Seminarium Duchownego we Włocławku, zaginął po wojnie. Kilka końcowych kart innego woluminu odnalazł w 2014 roku w Budapeszcie Marcin Jakubczyk. Zdefektowany druk ołomuniecki stanowi trzeci niezależny egzemplarz Dictionariusa. W połączeniu $\mathrm{z}$ fragmentem budapeszteńskim otwiera pole do badań nad jednym z pierwszych leksykograficznych zabytków języka polskiego, który nie doczekał się jak dotąd naukowego omówienia. 